DOI: http://dx.doi.org/10.23925/2176-2767.2020v69p517-524

Recebido em: 03/03/2020 Aprovado em: 10/08/2020

\title{
RESENHA
}

\section{ESTADO IMPERIAL, ORDENS RELIGIOSAS, SENHORES E ESCRAVOS EM UM CONTEXTO DE CRISE}

MOLINA, S. R. A morte da tradição: a Ordem do Carmo e os escravos da Santa contra o Império do Brasil (1850-1889). Jundiaí: Paco Editorial, 2016, 420 p.

\section{WILLIAM DE SOUZA MARTINS*}

Tradicionalmente, as décadas finais do Império foram estudadas a partir de uma sucessão de "questões", em que os conflitos entre a Igreja católica e a autoridade do imperador, assim como os debates em torno do uso do trabalho dos cativos e as iniciativas destes contrárias à escravidão, ocuparam um lugar de destaque. Possivelmente, um dos maiores méritos da obra de Sandra Rita Molina, que em sua primeira versão constituiu uma tese de Doutorado apresentada à Universidade de São Paulo, deve-se à articulação daqueles dois temas, antes vistos separadamente, no âmbito de um recorte específico: o problema da administração do patrimônio

\footnotetext{
* Doutor em História Social pela Universidade de São Paulo. Professor Associado do Instituto de História e do Programa de Pós-graduação em História Social da Universidade Federal do Rio de Janeiro. Laboratório Sacralidades (UFRJ). Orcid.org/0000-0002-8871-3771.
} 
imobiliário e dos cativos pertencentes à Província Carmelita Fluminense. Objeto de uma resenha anterior, que cuida particularmente de relacionar a contribuição da obra ao campo de estudos da escravidão, ${ }^{1}$ espera-se no presente texto aprofundar e indicar outras possibilidades de leitura do livro de Sandra Molina.

Com ênfase na análise dos conventos situados em São Paulo e em outras cidades e vilas paulistas, a base para o desenvolvimento da argumentação da autora foi propiciada pelo exame da documentação da Ordem do Carmo dispersa em vários acervos: no Arquivo Particular da Ordem, em Belo Horizonte; no Arquivo do Estado de São Paulo; e na riquíssima e ainda pouco explorada Coleção Eclesiástica do Arquivo Nacional do Rio de Janeiro. Em caráter complementar, a autora fez uso de diversos acervos locais, onde consultou principalmente registros da imprensa, e também os relatórios de ministros e de presidentes de província. Nesse trabalho de reconstituição meticuloso, a autora dialoga com uma relevante historiografia a respeito das relações entre Estado e Igreja católica desde as últimas décadas do século XVIII. À luz daquelas referências historiográficas e das análises da obra, é possível perceber que os problemas padecidos na Província do Carmo tinham relação direta com o padroado exercido pela Coroa portuguesa na esfera da administração eclesiástica, cujas prerrogativas foram mais tarde assumidas pelo Império brasileiro. Além da indicação dos ocupantes de diferentes benefícios eclesiásticos e do provimento do culto divino, desde os tempos do gabinete pombalino (1750-1777) a política da Coroa caracterizara-se

${ }^{1}$ BARBI, R. J. Catolicismo, escravidão e a resistência ao Império: um outro olhar. Almanack, n. 15, 2017, pp. 366-370. 
pelo regalismo, entendido como fortalecimento dos controles exercidos pelo padroado, especialmente sobre as ordens religiosas, que dispunham de maior autonomia. Assim, durante os reinados de D. José I, de D. Maria I e na regência do príncipe $\mathrm{D}$. João, sucederam-se diversas iniciativas da Coroa portuguesa em busca da limitação do número de religiosos nos claustros, de informações precisas sobre o patrimônio acumulado pelas congregações regulares e da venda de parte dos referidos bens, para saldar despesas administrativas da monarquia. ${ }^{2}$

No primeiro capítulo da obra, intitulado "O mundo entre os muros do convento", a autora mapeia as consequências de diferentes atos do Império, que restringiram o ingresso de noviços e a administração dos bens do clero regular, em particular da Ordem do Carmo. Assim, o projeto $\mathrm{n}^{\circ} 20$ de 1828 determinou o impedimento da entrada de noviços estrangeiros nas ordens regulares, estipulando também que a entrada de noviços nacionais dependeria de autorizações específicas da Assembleia Geral Legislativa. Retomando a medida anterior, o aviso de 19 de maio de 1855, publicado pelo ministro da Justiça de José Nabuco de Araújo,

\footnotetext{
${ }^{2}$ Para a segunda metade do século XVIII, o processo descrito foi detalhado em obra mais recente, que mantém um diálogo próximo com o trabalho de Sandra Molina: SILVA, L. F. L. Regalismo no Brasil colonial: a Coroa portuguesa e a Ordem do Carmo, Rio de Janeiro, 1750-1808. São Paulo: Intermeios: USP, 2018. A respeito das leis testamentárias editadas durante o gabinete pombalino, e que tiveram significativo impacto sobre os bens das ordens regulares e de outras associações religiosas, ver RODRIGUES, C. Intervindo sobre a morte para melhor regular a vida: significados da legislação testamentária no governo pombalino. In: RODRIGUES, C.; FALCON, F. (Orgs.). A "época pombalina" no mundo luso-brasileiro. Rio de Janeiro: FGV, 2015, pp. 307-345. Sobre as leis de desamortização, editadas durante a Regência de D. João, e que determinaram a venda compulsória de bens das corporações eclesiásticas, convertidas em apólices da Coroa portuguesa, ver ALEXANDRE, V. Os sentidos do Império: questão nacional e questão colonial na crise do Antigo Regime português. Porto: Afrontamento, 1993, pp. 87-89.
} 
determinava a reforma das ordens regulares, cujos termos seriam definidos em concordata com a Santa Sé. Além disso, o aviso suspendeu, por tempo indeterminado, a entrada de candidatos de quaisquer nacionalidades ao noviciado em mosteiros e conventos. A medida radical assumida pelo Império brasileiro, e inspirada pela longa tradição de práticas regalistas adotadas pela Coroa portuguesa, teve o efeito de reduzir ao número de cinco religiosos o total dos frades da Província, responsáveis pela administração de sete conventos (Rio de Janeiro, Ilha Grande, Vitória, São Paulo, Santos, Mogi das Cruzes e Itu) e de diversas propriedades rurais e urbanas. Nesse quadro de escassez, faltavam controles eficazes dos prelados da Província sobre o conjunto dos frades carmelitas, que se ausentavam das funções de culto e das atividades de administração, alegando doenças.

No que diz respeito à administração dos bens das ordens regulares, o Estado imperial produziu diversas medidas legais, com vistas a reduzir a autonomia das referidas corporações. Tais aspectos encontram-se detalhados no segundo capítulo, "Uma Gomorra na Corte: como o Estado imperial deveria agir com o clero regular?". Primeiramente, a lei de 9 de dezembro de 1830 determinou a anulação dos contratos envolvendo bens que, firmados pelas ordens regulares, não tivessem a expressa licença da monarquia. Como a autora mostrou com ampla variedade de evidências, a Província Carmelita Fluminense contrariou sistematicamente a lei. Aquela disposição legal foi renovada por meio do aviso do Ministério do Império de 15 de setembro de 1865, que tornava nulos os contratos onerosos das ordens regulares que não contassem com a licença imperial. Por fim, a lei de 28 de junho de 1870 
determinou a conversão dos bens das ordens, no prazo de dez anos, em apólices administradas pela monarquia. A medida igualmente não surtiu efeito, sendo mais uma vez renovada em 22 de dezembro de 1883. Não obstante a sucessão de medidas legais, que lhes traziam várias dificuldades, os frades do Carmo continuaram a garantir a administração dos bens da Província, recorrendo a diversas estratégias informais.

O controle sobre a propriedade e sobre a administração da mãode-obra escrava constituía parte importante das preocupações dos frades da Província. Depois de 1850, com a ação do Estado mais incisiva contra o tráfico africano, o preço dos escravos em poder dos religiosos se valorizou, o que deu origem a uma série de situações novas. Por um lado, surgiram queixas crescentes, por parte de arrendatários não eclesiásticos, em torno do aumento dos aluguéis de escravos domésticos arrendados aos conventos. Como se sabe, tais arrendamentos estavam impedidos por lei, e apenas se mantinham pelo interesse comum de frades e senhores leigos, obtendo os primeiros os recursos materiais de que necessitavam para fugir da asfixia imposta pelo Estado, e conseguindo os últimos a posse de escravos em condições muito vantajosas. Mesmo após 1871, no contexto da edição da Lei do Ventre Livre, e com o surgimento de iniciativas de abolição do cativeiro no âmbito das ordens regulares - com os religiosos beneditinos e franciscanos libertando os respectivos escravos - os frades carmelitas insistiram em manter os contratos de arrendamento. Assim, ao decidirem libertar os cativos da Ordem em 8 de dezembro de 1871, foram excluídos do conjunto aqueles que estavam submetidos a contratos de arrendamentos particulares, ou os que serviam nas fazendas. 
No capítulo três, intitulado, "honestas estratégias: o Carmo reorganizando seu patrimônio em função de sua sobrevivência", a autora aprofunda a análise das relações de cumplicidade que, constituídas por frades, arrendatários e escravos, permitiram à Província Carmelita Fluminense garantir a gestão de bens móveis e imóveis, ao arrepio das leis. Nesse contexto, os frades carmelitas enfrentaram dois importantes opositores. Em primeiro lugar, o Estado imperial, cujos relatórios ministeriais apresentavam imagens negativas dos religiosos, acusando-os de imorais, ociosos e de administradores incapazes, não atuando em prol da educação religiosa do povo. A inexistência de atividades missionárias na Província endossava as referidas críticas. A abertura de aulas públicas pelos carmelitas, na década de 1860, constitui uma tentativa de minorar os referidos questionamentos. Além do Estado, os religiosos do Carmo tornaram-se alvo das críticas da imprensa. Esta contrastava a vida confortável e ociosa desfrutada por alguns frades, em desrespeito aos votos de pobreza da vida religiosa, com a crueldade do tratamento que aplicavam aos escravos. Segundo as denúncias dos jornais, muitos cativos descendiam de índios escravizados ilegitimamente, devendo assim ser libertados. Alguns escravos padeciam situações de abandono material, o que criava condições para o rompimento do contrato da escravidão. A valorização da mão-de-obra escrava tinha o efeito de propiciar contínuas mudanças de arrendatários, o que gerava situações de tensão nos plantéis. ${ }^{3}$ A ruptura de relações costumeiras mantidas entre frades, arrendatários e

3 O referido tema mereceu uma abordagem já clássica na historiografia: CHALHOUB, S. Visões da liberdade: uma história das últimas décadas da escravidão na Corte. São Paulo: Cia. das Letras, 1990. 
escravos conduzia os últimos a diferentes tipos de reação: a fuga, o suicídio ou a rebelião.

No quarto capítulo, denominado "Frades feitores e os escravos da Santa", a autora aprofunda a análise das reações dos cativos, em um contexto marcado pela crescente hostilidade aos frades e à manutenção do cativeiro. O exame das estratégias de resistência dos cativos é conduzido a partir de estudos de casos, em que se destacam o assassinato do prior do Convento de São Paulo (1859) e o episódio da fazenda do Capão Alto, na Província do Paraná, ocorrido em torno de 1864. No primeiro caso, os escravos reagiram com violência contra o superior conventual que se caracterizava pelo caráter temperamental. No segundo caso, escravos que permaneciam há três gerações na mesma propriedade, e que desfrutavam de elevado grau de autonomia na mesma, recusaram obediência ao novo arrendatário, que se dispunha a leva-los a outra propriedade. Segundo os autos criminais, os escravos "estavam resolvidos a não seguir adiante enquanto não fosse ordenado por Nossa Senhora, de quem só eram escravos" (MOLINA, 2016, p. 277, grifos da autora). De acordo com as análises de Molina, "tais escravos pareciam ter compreendido a especificidade de sua escravidão, pois eram fruto de doações a uma instituição religiosa que se colocava como intermediária entre a divindade, Nossa Senhora do Carmo, e os homens leigos e pecadores" (MOLINA, 2016, p. 276). Nesse caso interessantíssimo, os escravos se colocavam sob a proteção da Santa para resistir às iniciativas dos arrendatários.

Acuada cada vez mais pelas medidas restritivas adotadas pelo Império, externamente a Província Carmelita Fluminense garantiu sua sobrevivência material por meio de arranjos informais junto a 
arrendatários e, no plano interno, junto aos próprios cativos. Não obstante, agravando-se a possibilidade de utilização da mão-de-obra nas fazendas e nos conventos segundo as condições costumeiras, a autora mostra como, aos poucos, foi se dissolvendo a trama, urdida a partir de relações de amizade e de troca de favores. Por isso, a obra de Sandra Molina fornece uma contribuição substancial para a compreensão do regalismo, das ordens religiosas e da crise da escravidão nas décadas finais do Império. 